\title{
Hypertension of neurogenic origin: effect of microvascular decompression of the CN IX-X root entry/exit zone and ventrolateral medulla on blood pressure in a prospective series of 48 patients with hemifacial spasm associated with essential hypertension
}

\author{
Marc Sindou, MD, DSc, ${ }^{1}$ Mohamed Mahmoudi, MD, ${ }^{1,2}$ and Andrei Brînzeu, MD ${ }^{1,3}$ \\ ${ }^{1}$ Department of Neurosurgery, University of Lyon 1, Hôpital Neurologique "Pierre Wertheimer," Lyon, France; 2Section of \\ Neurosurgery, Regional Military Hospital of Oran (HMRUO), Oran, Algeria; and 3University of Medicine "Victor Babes," \\ Timisoara, Romania
}

OBJECT In spite of solid anatomical and physiological arguments and the promising results of Jannetta in the 1970s, treating essential hypertension by microvascular decompression (MVD) of the brainstem has not gained acceptance as a mainstream technique. The main reason has been a lack of established selection criteria. Because of this, the authors' attempts have been limited to patients referred for MVD for hemifacial spasm (HFS) who also had hypertension likely to be related to neurovascular compression (NVC).

METHODS Of 201 patients referred for HFS, $48(23.8 \%)$ had associated hypertension. All had high-resolution MR images that demonstrated NVC. All underwent MVD of the root exit/entry zone (REZ) of the ninth and tenth cranial nerves (CN IX-X) and adjacent ventrolateral medulla in addition to the CN VII REZ. Effects on hypertension, graded using the WHO classification, were studied up to the latest follow-up, which was 2-16 years from the time of surgery, 7 years on average. Also, effects of MVD on blood pressure (BP) according to the side of vascular compression were evaluated.

RESULTS Preoperatively, hypertension was severe in all but 1 of the patients; in spite of medical treatment, 47 patients still had WHO Grade 1 or 2 hypertension, and 18 still had unstable BP. After MVD, at latest follow-up, BP had returned to normal (i.e., systolic pressure $<140 \mathrm{~mm} \mathrm{Hg}$ ) in 28 patients; 14 of these patients $(29.10 \%$ of the whole series) were able to maintain normal BP without any antihypertensive treatment; the other 14 still required some medication to maintain their BP below $140 \mathrm{~mm} \mathrm{Hg}(p<0.0001)$. Also, at latest follow-up, BP remained unstable in only 8 of the 18 patients with instability prior to MVD $(p<0.02)$.

Analysis according to side of compression showed that of the 30 patients with left-sided compression, 17 had their BP normalized (without medication in 11 cases), and of the 18 patients with right-sided compression, 11 had their BP normalized (without medication in 3 cases). The difference between sides was not significant.

CONCLUSIONS These results argue for considering MVD for the treatment of hypertension likely to be due to NVC at the CN IX-X REZ and adjacent ventrolateral medulla. Criteria for selecting patients with hypertension alone still need to be established and could include the following indications: apparently essential hypertension, likely to be neurogenic, in patients in whom high-resolution MRI shows clear-cut images of NVC at the CN IX-X REZ and adjacent ventrolateral medulla and in whom BP cannot be controlled by medical treatment.

http://thejns.org/doi/abs/10.3171/2014.12.JNS141775

KEY WORDS essential arterial hypertension; glossopharyngeal nerve; medulla oblongata; microvascular decompression; neurovascular compression; neurogenic mechanism of hypertension; vagus nerve; functional neurosurgery

ABBREVIATIONS AICA = anterior inferior cerebellar artery; $\mathrm{BA}=$ basilar artery; $\mathrm{BP}=$ blood pressure; $\mathrm{CN}=$ cranial nerve; $\mathrm{ENMG}=$ electroneuromyographic; $\mathrm{GP}=$ general practitioner; HFS = hemifacial spasm; MVD = microvascular decompression; NVC = neurovascular compression; PICA = posterior inferior cerebellar artery; REZ = root entry/exit zone; $\mathrm{VA}=$ vertebral artery.

SUBMITTED August 1, 2014. ACCEPTED December 30, 2014.

INCLUDE WHEN CITING Published online July 31, 2015; DOI: 10.3171/2014.12.JNS141775.

DISCLOSURE The authors report no conflict of interest concerning the materials or methods used in this study or the findings specified in this paper. 
$\mathrm{N}$ EUROVASCULAR compression (NVC) of the ventrolateral medulla was postulated to be a cause, among others, of essential hypertension by Jannetta's group in the late $1970 s .{ }^{26,47}$ Since then only a few studies on this cause and its treatment, either clini$\mathrm{cal}^{20,27,29,32,33,38}$ or experimental,,$^{27,47-49}$ have been reported in the literature despite the possibility that such a neurogenic mechanism might be implicated in a relatively large number of patients. The literature affords robust anatomical/ physiological evidence that compression of the ninth and tenth cranial nerve (CN IX-X) root entry/exit zone (REZ) and adjacent ventrolateral medulla-especially on the left side, known to convey inputs from the baroreceptors of the (left-sided) cardiac atrium - could be the origin of systemic arterial hypertension. . $3,4,6,8,9,11,15,16,18,22,23,25,42-44$

In the quest for patients affected with essential hypertension to be candidates for vascular decompression, as many as 14 studies have been conducted to investigate the reliability of MRI for the detection of compressive vessels with a potential role in the genesis of hypertension. ${ }^{1,10,12}$, $21,24,28,35,37,39,45,50,57,58,61$ In most of these publications, images of vascular contact/compression at the ventrolateral medulla were reported at a higher rate in patients with hypertension than in those with normal blood pressure (BP). However, statistical significance was absent when the analysis was restricted to prospective studies. ${ }^{7}$

Because of the absence of established criteria for surgical exploration of the posterior fossa and vascular decompression in patients with only hypertension, apparently essential, we began treating hypertension with microvascular decompression (MVD) only in patients with primary hemifacial spasm (HFS) associated with hypertension. Surgery consisted of performing MVD at the ventrolateral medulla and the CN IX-X REZ in addition to the CN VII REZ. The effects of MVD on BP in this group of patients is the subject of the present report.

\section{Methods \\ Patient Selection}

Patients included in the study fulfilled the following criteria. 1) Primary HFS (i.e., strictly unilateral) with typical clinical presentation, without any specific etiology determined by ophthalmological, otorhinolaryngological, and cervicomaxillofacial inventories or MRI exploration, and confirmed to be of a non-postparalytic nature according to the results of electroneuromyographic (ENMG) examination. 2) Essential hypertension according to criteria for diagnosis of hypertension, a baseline systolic pressure greater than $140 \mathrm{~mm} \mathrm{Hg}$ and a baseline diastolic pressure greater than $90 \mathrm{~mm} \mathrm{Hg}$. These criteria were derived from the $\mathrm{WHO}$ classification ${ }^{60}$ and correspond to the more recent guidelines of the WHO International Society of Hypertension $^{59}$ as well as of the European Society of Hypertension. ${ }^{19}$ Hypertension was qualified as essential (i.e., primary) after elimination of all identifiable etiologies, including any rise in BP induced by pharmacological treatment(s). ${ }^{19,59}$ 3) Probability of compression of not only CN VII but also the CN IX-X REZ and adjacent ventrolateral medulla demonstrated by high-resolution 3D T2-weighted and 3D gadolinium-enhanced T1-weighted
MRI as well as 3D time-of-flight MR angiography, in association. ${ }^{30,31}$ 4) General condition good enough to enable the patient to undergo surgery without unreasonable risks. Cardiovascular status was checked at our institutions' preanesthesia outpatient clinic, according to the international standard recommendations.

Before being enrolled in this prospective study, patients had to sign an informed consent form that described the specific risks of the CN VII (together with the nearby $\mathrm{CN}$ VIII) nerve MVD procedure and, in addition, the risks entailed by the manipulation of the $\mathrm{CN}$ IX-X complex. The lack of certainty regarding a positive effect on hypertension was also mentioned.

\section{Surgical Procedure and Anatomical Findings}

The surgery was basically of the classical MVD type for HFS, that is, decompression of the facial nerve (CN VII) REZ through a retromastoid, retrosigmoid, infraflocular approach to access the CN VII REZ ventrocaudally at the brainstem, where vascular compression of the nerve is usually located. ${ }^{41,54}$ Exposure, dissection, and decompression started at the medullary level, ventral to the $\mathrm{CN}$ $\mathrm{X}-\mathrm{IX}$ rootlets, to reach the CN VII REZ ventrocaudally. Vascular relationships with the REZ of CN VII and the CN IX-X complex, together with the adjacent ventrolateral medulla, were carefully noted in the operative report.

\section{Assessment of the Effects of MVD on BP}

All of the enrolled patients with hypertension had a documented follow-up of at least 2 years. For the study, data were collected by an independent observer (M.M.) through a telephone interview of the patient and if necessary the general practitioner (GP).

All patients in the series were being treated with antihypertensive medications at the time they were referred for surgical treatment of HFS. For safety (and also methodological) reasons, the decision was made not to discontinue or modify medications for MVD surgery .

Preoperative $\mathrm{BP}$ values were measured at rest the day before surgery. Measurements were taken by the admission nurse, with a delay of several hours after arrival of the patient. The measurements were considered valid in all cases in this series because they were in general agreement with the BP values considered the usual ones, according to the GP's letter of referral.

For the postoperative study, BP values were the ones regularly measured and transmitted by the patient's GP.

The degree of severity of hypertension was graded according to the International WHO classification ${ }^{59,60}$-i.e., Grade 1 for systolic BP of 140-159 mm Hg, Grade 2 for systolic BP $160-179$ mm Hg, Grade 3 for systolic BP $\geq 180$ $\mathrm{mm} \mathrm{Hg}$. Both the systolic and the diastolic values were considered in determining grades; when there was any hesitation in choosing between grades, for simplification the systolic value was preferably retained. Also the stable or unstable character of the hypertension as reported by the GP was noted.

For each patient, antihypertensive medication, of all classes, as well as any withdrawal or eventual modifications between preoperative evaluation and latest follow-up interview, was recorded. 
Effects of MVD on hypertension were calculated by comparing preoperative BP values (obtained while patients were being treated with antihypertensive medication) and BP values obtained at the most recent postoperative follow-up evaluation.

The effect of MVD on hypertension was also evaluated according to the side of the vascular decompression.

\section{Assessment of the Effects of MVD on HFS}

Assessment of the effects on the HFS was performed by the senior surgeon (M.S.) at discharge, on average the 10th postoperative day, and then at the first outpatient visit, 2-3 months after the surgery. Also at the first outpatient visit all patients had an ENMG exploration of the facial nerve, performed by the same neurologist who performed the preoperative ENMG examination. Clinical evaluation and ENMG examination were repeated at 1 year in all cases, and additional follow-up (continuing past the 1st year) was provided for patients who did not obtain an early satisfactory result. The final 2012 evaluation was made by the independent observer (M.M.) through telephone interview.

The effect was considered excellent (Class Ia) when there was no residual spasm and the ENMG did not show any ephaptic abnormalities and good (Class Ib) when the patient estimated that he or she was no longer disturbed by the disease in spite of occasional twitches under intense emotional events and/or still had some synkinetic activity at ENMG exploration. Relief that qualified as excellent or good was regrouped as "satisfactory outcome."

The effect was considered fair (Class II) when bothersome twitches persisted in spite of an overall improvement (in intensity and frequency) of $50 \%$ or more.

The effect was considered poor (Class III) when relief was less than $50 \%$, leaving disabling manifestations, and nil (Class IV) when there was no improvement. Poor effect and no effect were regrouped as failure.

\section{Statistical Study}

Data were presented as numbers of patients (\%) and were compared between the cohorts of patients with and without hypertension by means of the chi-square test or Fisher exact test. Paired comparisons were performed using the paired t-test or Bhapkar test.

\section{Results}

From early 1995 to the end of 2009 a total of 201 patients were referred with the diagnosis of primary HFS and underwent MVD of CN VII after MRI demonstrated clearcut vascular compression(s) at the REZ. Of those patients, $48(23.9 \%)$ also had hypertension that was considered essential. In addition to MVD of CN VII, these patients all underwent decompression of the ipsilateral CN IX-X and neighboring ventrolateral medulla. Only this group of 48 patients was enrolled for the study of the effects of MVD on hypertension. Demographic characteristics and anatomical findings at surgery, namely compressive vessels, were compared between the group of 48 patients with HFS and hypertension and the group of 153 patients with HFS without hypertension. As shown in Table 1, there was no statistically significant difference between the 2 groups with respect to demographic characteristics. As regards compressive vessels, predominance of a posteroinferior cerebellar artery in the group of patients with hypertension had a tendency toward significance.

\section{Demographic Features of the Patients With Hypertension}

At surgery, the age of the 48 patients with hypertension ranged from 35 to 82 years (average 59 years). Twenty-six $(54.16 \%)$ of the patients were male and $22(45.83 \%)$ were female (Table 1).

\section{Characteristics of the HFS}

The duration of symptoms (HFS) prior to surgery ranged from 2 to 20 years (average 5 years). According to selection criteria, the spasm was primary, typical, and severely disabling after an average of 5 years of evolution. Spasms were on the left side in 30 patients $(62.50 \%)$ and on the right in $18(37.50 \%)$. Thirty-five patients (72.9\%) had had Botulinum toxin injections, to which they became resistant or intolerant. The 13 others had preferred to undergo surgery without initially trying Botulinum toxin therapy.

\section{Characteristics of the Hypertension}

The 48 enrolled patients had chronic, apparently es-

TABLE 1. Demographic characteristics and anatomical findings (compressive vessels) at surgery in the groups of patients with HFS with and without hypertension*

\begin{tabular}{|c|c|c|c|}
\hline Variable & $\begin{array}{c}\text { HFS w/ HT } \\
(n=48)\end{array}$ & $\begin{array}{l}\text { HFS w/o HT } \\
(n=153)\end{array}$ & $p$ Value \\
\hline Sex & & & NS \\
\hline Female & $22(46)$ & $89(58)$ & \\
\hline Male & $26(54)$ & $64(42)$ & \\
\hline Age in yrs & & & NS \\
\hline Range & $35-82$ & $30-80$ & \\
\hline Average & 60 & 53 & \\
\hline Side & & & 0.8315 \\
\hline Right & $18(37.5)$ & $60(39)$ & \\
\hline Left & $30(62.5)$ & $93(61)$ & \\
\hline Compressive vessel(s) & & & 0.0036 \\
\hline VA/BA & $2(4)$ & $41(27)$ & \\
\hline PICA & $12(25)$ & $31(20)$ & \\
\hline AICA & $15(31)$ & $24(16)$ & \\
\hline AICA + PICA & $5(10)$ & $19(12)$ & \\
\hline $\mathrm{VA} / \mathrm{BA}+\mathrm{PICA}$ & $10(21)$ & $16(10)$ & \\
\hline $\mathrm{VA} / \mathrm{BA}+\mathrm{AICA}$ & $1(2)$ & $14(9)$ & \\
\hline $\mathrm{VA} / \mathrm{BA}+\mathrm{PICA}+\mathrm{AICA}$ & $3(6)$ & $8(5)$ & \\
\hline \multicolumn{4}{|l|}{$\begin{array}{l}\text { Implicated vessel (alone or in } \\
\text { association) }\end{array}$} \\
\hline VA/BA & $16(33)$ & $79(52)$ & 0.0267 \\
\hline PICA & $30(63)$ & $74(48)$ & 0.0873 \\
\hline AICA & $24(50)$ & $65(42)$ & NS \\
\hline Presence of multiple conflicts & $19(40)$ & $57(37)$ & NS \\
\hline
\end{tabular}

NS = not significant

* Data are given as numbers of cases (\%) unless otherwise indicated. 
sential, hypertension. At origin, before the introduction of antihypertensive medication, the hypertension was classified as WHO Grade 1 in 22 cases (45.83\%), Grade 2 in 22 (45.83\%), and Grade 3 in 4 (8.33\%) (Table 2). Of the 48 patients, 39 (80.13\%) had unstable BP (Table 2 and Fig. 1).

All 48 patients were treated by their GP and if necessary a cardiologist, according to national health recommendations. At the time of the surgery, 15 patients $(31.25 \%)$ were being treated with a single class of antihypertensive drug, $29(60.42 \%)$ were being treated with 2 classes, and $4(8.33 \%)$ were receiving tritherapy.

Under medical treatment, BP values had improved in a majority of patients, However, in spite of apparently wellconducted treatment, basal BP values stayed higher than normal-WHO Grade 1 in 38 patients and WHO Grade 2 in 9 (Table 2). However, overall average WHO grade was diminished from 1.63, before, to 1.19 , after initiation of antihypertensive treatment (Table 2). In spite of the medical treatment, BP remained unstable in 18 of the 39 patients who had unstable BP at diagnosis of hypertension (Table 2 and Fig. 1). In summary, at the time of the surgery, on medication, only 1 patient $(2.08 \%)$ had systolic $\mathrm{BP}$ in the normal range (i.e., under $140 \mathrm{~mm} \mathrm{Hg}$ ), 38 patients (79.10\%) had Grade 1 hypertension, 9 (18.75\%) had Grade 2 hypertension, and none had Grade 3.

\section{Findings at Surgery}

A detailed list of the compressive vessels found at surgery is given in Table 1 . Among the 48 patients, 19 $(39.50 \%)$ had more than 1 compressive vessel. The vertebral artery (VA) and/or basilar artery (BA) was implicated in $16(33.33 \%)$ of the 48 patients, the posterior inferior cerebellar artery (PICA) in $30(62.50 \%)$, and the anterior inferior cerebellar artery (AICA) in $24(50 \%)$. In all of the 48 patients, the conflicting vessels exerted the compressive effect ventrally at the REZ of both the facial nerve and the neighboring $\mathrm{CN}$ IX-X rootlets and adjacent ventrolateral medulla.

TABLE 2. Results of MVD on hypertension at latest follow-up, according to the WHO classification*

\begin{tabular}{|c|c|c|c|c|}
\hline $\mathrm{BP}(\mathrm{mm} \mathrm{Hg})$ & $\begin{array}{l}\text { At Dx } \\
\text { of HT }\end{array}$ & Pre-MVD & Post-MVD & p Valuef \\
\hline Category & & & & $<0.0001$ \\
\hline Normal: <140 & $0(0)$ & $1(2)$ & $28(58) \dagger$ & \\
\hline Grade $1 \mathrm{HT}: 140-159$ & $22(46)$ & $38(79)$ & $18(38)$ & \\
\hline Grade 2 HT: $160-179$ & $22(46)$ & $9(19)$ & $1(2)$ & \\
\hline Grade $3 \mathrm{HT}:>180$ & $4(8)$ & $0(0)$ & $1(2)$ & \\
\hline Averaged WHO grade & 1.63 & 1.19 & 0.48 & $<0.0001$ \\
\hline Unstable & $39(80)$ & $18(38)$ & $8(16)$ & 0.02 \\
\hline \multicolumn{5}{|c|}{$\begin{array}{l}\text { Dx = diagnosis; } H T=\text { hypertension } \\
\text { * Data are presented as numbers of patients (\%). BP values are systolic. All } \\
\text { pre-MVD BP measurements were obtained with patients on antihypertensive } \\
\text { medication. Post-MVD BP is based on measurements obtained at the latest } \\
\text { follow-up evaluation. } \\
\dagger \text { Of the } 28 \text { patients with normal systolic BP after MVD, } 14 \text { were not taking any } \\
\text { antihypertensive medication, } 10 \text { were following a reduced treatment regimen, } \\
\text { and } 10 \text { were following the same treatment regimen as before surgery. } \\
\ddagger \text { Based on Bhapkar test for qualitative scoring and paired t-test for average } \\
\text { score. }\end{array}$} \\
\hline
\end{tabular}

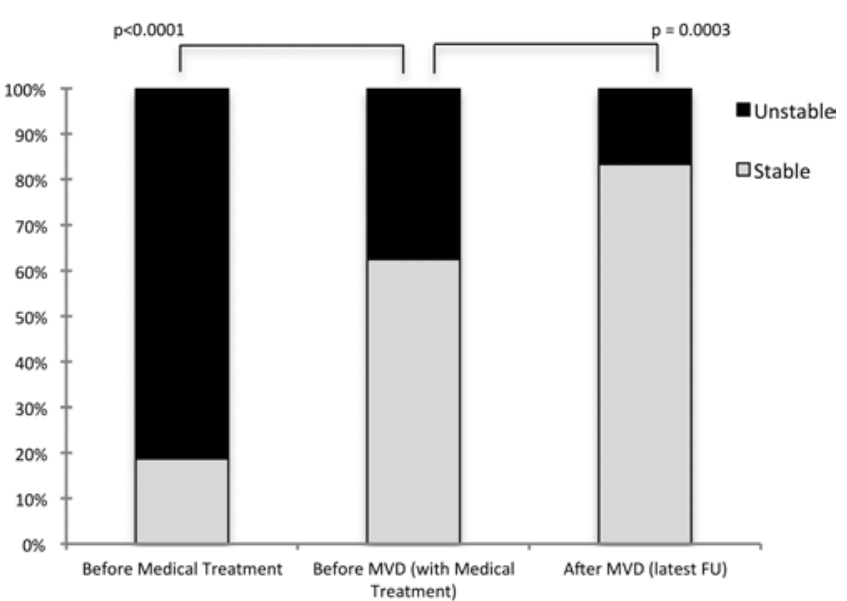

FIG. 1. Repartition of BP according to stability/instability. Note the highly significant gain with medical treatment $(p<0.0001$, Bhapkar test) and also a significant gain with MVD ( $p=0.0003$, Bhapkar test). FU = follow-up.

\section{Effects of MVD on Hypertension}

All 48 enrolled patients had at least 2 years of documented follow-up. Forty-four patients were directly accessible through telephone interview at the time of the study. Two patients had died ( 3 years after MVD in 1 case and 5 years after MVD in the other) and information was provided by their relatives. In both cases, death was due to a disease that had developed subsequent to the MVD procedure and was unrelated to either that procedure or hypertension. Two patients had been lost to follow-up by the time of the study, but adequate information was available for at least 2 years after surgery ( 2 years in 1 case and 3 years in the other).

Table 2 shows favorable effects of MVD on BP. At the most recent follow-up evaluation (an average of 7 years after MVD, range 2-16 years), BP was normal (systolic pressure $<140 \mathrm{~mm} \mathrm{Hg}$ ) in 28 patients-that is, in 58.33\% of the series $(\mathrm{p}<0.0001)$. Of the 28 patients in whom BP had normalized, 14 (29.10\% of the whole series) had their antihypertensive treatment totally withdrawn, whereas the 14 others $(29.10 \%)$ were still being treated with antihypertensive medication, but with a reduced regimen in 10 cases. Treatment was considered notably reduced when at least 1 class of medication could be suppressed from the association of several classes and/or doses of the medications were diminished by at least half, globally.

Also, at the latest post-MVD follow-up, the average WHO grade was decreased to 0.48 from 1.19 , the value prior to surgery calculated from BP measurements obtained when patients were under medical treatment $(\mathrm{p}<$ 0.0001) (Table 2).

In addition, Fig. 1 shows that after MVD the number of patients with unstable BP was reduced, namely from 18 patients $(37.50 \%)$ before MVD (under medical treatment) to 8 patients $(16.67 \%)$ after MVD $(\mathrm{p}=0.00038)$.

The effects of MVD on hypertension according to the preoperative grade of treated hypertension were as follows at latest follow-up. Among the 38 patients with Grade 1 $\mathrm{BP}$, preoperative Grade $1 \mathrm{BP}$ normalized in 23 patients $(61.29 \%)$ but remained at the same Grade 1 level as before MVD in 15, with the necessity of continuing antihyperten- 
sive medication. Of the 9 patients with preoperative Grade 2 hypertension, 4 experienced normalization of BP (gaining 2 classification levels) and 3 experienced improvement to Grade 1; of the other 2 patients, one continued to have Grade 2 hypertension, and in the other, the grade of hypertension rose to Grade 3.

The effects of MVD on BP over time were evaluated by comparing WHO grades at 1 year after surgery and at latest follow-up. The results show a favorable delayed effect in a number of patients; in 8 patients, BP shifted to normal after the 1st year of follow-up (Fig. 2).

The effects of MVD on BP were also evaluated according to the side of vascular compression (Table 3). Thirty $(62.50 \%)$ of the 48 patients had surgery on the left side and $18(37.50 \%)$ on the right. As shown in Table 3, BP had normalized at latest follow-up in 17 of the 30 patients with left-sided compression; in 11 of these 17, antihypertensive medication could be withdrawn, while in the 6 others, treatment was maintained but at reduced doses. Among the 18 patients with right-sided compression, at latest follow-up BP had normalized in 11; in 3 of these 11, antihypertensive medication could be withdrawn, while in the 8 others treatment was maintained. The difference between sides was not statistically significant $(\mathrm{p}=0.14)$.

\section{Effects of MVD on HFS}

The effects of MVD on HFS over time- up to the latest follow-up, 2-16 years (average 7 years) after surgery-are summarized in Table 4 . The degree of relief at the latest follow-up was classified as Ia (excellent) in 34 patients (70.83\%) and $\mathrm{Ib}$ (good) in $8(16.66 \%)$, which corresponds to an overall satisfactory effect (Class I) in $87.50 \%$ (42 patients). A fair outcome (Class II) was observed in 2 patients (4.16\%). A poor outcome (Class III) and no relief at all (Class IV), both considered failure, was recorded in $8.32 \%$ of cases ( 2 patients having results in each of these 2 categories).

Delayed improvement and recurrence were seen in 8 and 2 patients, respectively. Thus, although a satisfactory

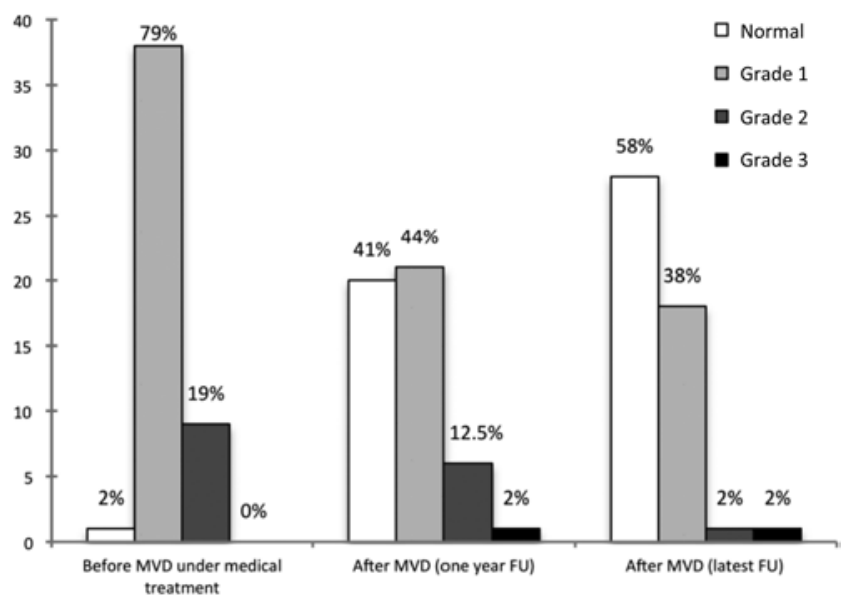

FIG. 2. Effect of MVD on WHO hypertension grades over time, with delayed improvements. One year after MVD, the grades were significantly lower ( $p$ < 0.0001). The same held true at the most recent follow-up ( $p$ $<0.0001$ ). However there was no statistically significant difference between 1 year and latest follow-up ( $p=0.12$, chi-square test).
TABLE 3. Effects of MVD on hypertension, according to side of compression and surgery*

\begin{tabular}{lrr}
\hline \multicolumn{1}{c}{ Outcome } & $\begin{array}{r}\text { Left Side } \\
(\mathrm{n}=30)\end{array}$ & $\begin{array}{c}\text { Right Side } \\
(\mathrm{n}=18)\end{array}$ \\
\hline Normalization w/ no need for medication & $11(36.7)$ & $3(16.7)$ \\
\hline Normalization w/ medication (at lower doses) & $6(20.0)$ & $8(44.4)$ \\
\hline No normalization & $13(43.3)$ & $7(38.9)$ \\
\hline
\end{tabular}

* Values are numbers of patients (\%). There was no significant difference with respect to side $(p=0.1422)$.

effect was observed in $75 \%$ of the patients at discharge and in $79.17 \%$ at the first outpatient visit, the rate of satisfactory effect increased to $87.50 \%$ at the latest follow-up. For the 8 patients who had a delayed satisfactory effect (16.66\% in the series), improvement appeared within the 1 st year in 6 and as late as the term of the 3rd postoperative year in 2 . Conversely a true recurrence-that is, reappearance of a disabling spasm after an initial satisfactory outcome at the first outpatient visit-was observed in 2 patients (4.14\%).

\section{Complications of Surgery}

Complications of surgery in the 48 patients are listed in Table 5. There was no mortality. Permanent neurological disturbances included swallowing difficulty and vocal cord paresis (occurring at a rate of $2 \%$ ), hearing deficit $(4 \%)$, and equilibrium disturbance $(2 \%)$.

\section{Discussion}

The present results suggest a favorable influence of vascular decompression on hypertension due to NVC in the CN IX-X REZ and adjacent medulla.

In our series of 48 patients, hypertension was severe in most cases, as shown in Table 2, and frequently unstable, as shown in Fig. 1. In all but one of the patients, hypertension was of Grade 1 or worse in spite of an apparently well-conducted medical treatment. After MVD, at latest follow-up, BP was normalized in 28 patients $(58.33 \%$ ) (p $<0.0001$ ). Medication could be totally withdrawn in 14 of these 28 patients and substantially reduced in more than two-thirds of the 14 others. In addition, MVD significantly decreased BP instability, as shown in Fig. 1 ( $p=0.00038)$.

TABLE 4. Degree of relief of HFS after MVD*

\begin{tabular}{cccc}
\hline Effect of MVD & At Discharge & $\begin{array}{c}\text { At 1st Outpatient } \\
\text { Visit }\end{array}$ & $\begin{array}{c}\text { At Latest } \\
\text { Follow-Up† }\end{array}$ \\
\hline Satisfactory & $36(75)$ & $38(79.2)$ & $42(87.5)$ \\
\hline Excellent (la) & $21(43.8)$ & $32(66.7)$ & $34(70.8)$ \\
\hline Good (Ib) & $15(31.2)$ & $6(12.5)$ & $8 .(16.7)$ \\
\hline Fair (II) & $10(20.8$ & $7(14.6)$ & $2(4.2)$ \\
\hline Failure & $2(4.2)$ & $3(6.3)$ & $4(8.3)$ \\
\hline Poor (III) & $0(0)$ & $1(2.1)$ & $2(4.2)$ \\
\hline Nil (IV) & $2(4.2)$ & $2(4.2)$ & $2(4.2)$ \\
\hline
\end{tabular}

* Values are numbers of patients (\%).

$\dagger$ Timing of latest follow-up ranged from 2 to 16 years after surgery (average 7 years). 
TABLE 5. Complications associated with combined MVD of CN IV REZ, CN IX-X REZ, and ventrolateral medulla in 48 patients

\begin{tabular}{ll}
\hline \multicolumn{1}{c}{ Complication } & No. of Patients (\%) \\
\hline Mortality & None \\
\hline Neurological morbidity & \\
\hline \multicolumn{1}{c}{ Difficulty in swallowing, vocal cord paresis } & $\mathrm{T}: 2 ; \mathrm{P}: 1(2 \%)$ \\
\hline Hearing loss & $\mathrm{P}: 2(4 \%)$ \\
\hline Dizziness & $\mathrm{P}: 1(2 \%)$ \\
\hline Facial paresis & $\mathrm{T}: 2$ \\
\hline Wound complications & \\
\hline \multicolumn{1}{c}{ Rhinorrhea } & $\mathrm{T}: 1$ \\
\hline Pseudomeningocoele & $\mathrm{T}: 1$ \\
\hline Infection (antibiotics) & $\mathrm{T}: 1$ \\
\hline Systemic complications & None \\
\hline
\end{tabular}

$\mathrm{P}=$ permanent complication; $\mathrm{T}=$ transient.

The question of undertreatment of hypertension prior to MVD surgery has to be raised. It is true that with antihypertensive treatment 38 of our patients had WHO Grade 1 hypertension, 9 had Grade 2, and 18 still had unstable BP. Notably, in most patients hypertension was severe (Grade 2 or 3 in 54\%) and unstable (in 80\%) before introduction of the medical treatment. After medical treatment was initiated, BP stabilized in 21 patients, and the average WHO grade improved from 1.63 to 1.19 . We did not critically evaluate the antihypertensive treatment prescribed by the GPs, but our institution's anesthesiologist checked the adequacy of treatment on the occasion of the preanesthesia outpatient clinic visit. To avoid introducing bias in the evaluation of the MVD effect, no change was made to the preoperative antihypertensive treatment.

Although the 48 patients enrolled in this study were operated on for a disease other than hypertension, namely HFS, we estimate that the favorable effect obtained by MVD on BP allows for consideration of MVD as a potential treatment for hypertension in cases in which it is likely to be neurogenic and due to vascular compression at the brainstem. Our results corroborate the pioneering work of Jannetta's group ${ }^{26,27}$ and the results obtained in Falbusch's series. ${ }^{20}$

In all of our patients, surgical exploration was conducted in the same manner as for CN VII REZ decompression for sole HFS: first, exposure of the CN X-IX rootlets and, deeply, the lateral medullary sulcus, and then, upward, exposure of the CN VII REZ at the brainstem. Whatever the responsible artery (or arteries) - VA/BA, AICA, or PICA (the latter being the most frequent) - the compression was always found ventral to the CN X-IX REZ and ventrocaudal to the CN VII REZ. In $40 \%$ of the cases, more than one vessel was considered likely to be causing compression.

Of paramount importance, decompression of the $\mathrm{CN}$ X-IX REZ and adjacent ventrolateral medulla did not require more extensive exposure than the exposure required for HFS treatment. As with current decompression for HFS, the approach was inferolateral to the cerebellum to open the arachnoid, first posteriorly to the CN X-IX rootlets and to reach their REZ ventrally, and then to the $\mathrm{CN}$
VII REZ ventrocaudally. The trajectory was infrafloccular, along the choroid plexus, and obliquely, from below, so as not to stretch the CN VIII nerve complex and the labyrinthine artery. ${ }^{5,34,41,46,54}$

Although not the topic of this paper, the effects of MVD on HFS were also evaluated. A satisfactory outcome was obtained in $87.5 \%$ of the patients.

According to classical anatomical/physiological knowledge, neurogenic hypertension is more likely to occur when dysfunction involves the left side of the brainstem (see Sindou, 2015, ${ }^{51}$ for review). In our series of 48 patients, the left side was implicated in $62.5 \%$. This percentage is quite similar to the percentage (61\%) in our group of 153 patients affected with HFS without hypertension $(p=0.83)$. In our series, efficacy of the decompression on hypertension was not significantly different between sides $(p=0.14)$. However, the percentage of normalization of BP without the need to maintain treatment was slightly better in the patients with the pathology on the left side $(36.7 \%)$ than in those with the pathology on the right (16.7\%), although this difference was not statistically significant.

Several publications have addressed the question of the prevalence of hypertension in patients with HFS compared with the general population of the same age range, with some investigating the side of the potentially responsible NVC by means of MRI. While some reported studies showed a higher prevalence of hypertension in patients with HFS than in control groups ${ }^{17,40}$ (as high as in $67 \%$ in patients with $\mathrm{HFS}^{40}$ ), others did not find any statistically significant differences (Colosimo et al., $47.3 \%$ vs $52.7 \%: 13,14$ and Tan et al., $42.7 \%$ vs $39.1 \%{ }^{56}$ ). Discrepancies between these studies might be due to bias in methodology: prevalence studies were retrospective and/or lacked proper matching with controls. In our global series of patients referred for surgery for their HFS, the percentage of patients with hypertension was $23.8 \%(n=48)$. Hypertension was present in $26.11 \%$ of the patients with left-sided HFS and in $20 \%$ of those with right-sided HFS, which is not a statistically significant difference.

In an important study by Nakamura et al. ${ }^{37}$ there was no significant difference in prevalence of hypertension between patients with HFS $(n=82)$ and a control group without HFS ( $\mathrm{n}=82$, matched for age and sex): $39 \%$ versus $29.3 \%(p=0.19)$. There was also no difference in the prevalence of hypertension between the patients with left-sided $(n=44)$ and right-sided $(n=38)$ HFS: $32 \%$ versus $47 \%$. But there was a significant difference when the side of the HFS and the presence or absence of hypertension were considered together; vascular compression at the ventrolateral medulla was observed on MRI in $86 \%$ of the patients with left HFS who had hypertension $(n=14)$ versus only $33 \%$ of the patients with left HFS without hypertension $(n=30)(p$ $=0.0012$ ). There was no such significant difference in patients with right HFS ( $p=0.18)$. Nakamura et al. concluded that these findings are of clinical importance, at least for the patients harboring left HFS and hypertension, and also for those with sole essential hypertension provided MRI shows vascular compression at the brainstem.

In a previously studied personal series of 362 patients affected with trigeminal neuralgia who underwent MVD, $26.8 \%$ of the patients had hypertension, and the average age 
of this subgroup was 61 years. ${ }^{53,52}$ These findings do not differ statistically in comparison with the findings for our series of 201 MVD for HFS, with $23.8 \%$ of the patients having hypertension at an average age of 53 (chi-square $\mathrm{p}$ $=0.44$ ). The influence of MVD on hypertension in association with trigeminal neuralgia was not studied in our series. Of note, while the ventrolateral medulla was decompressed in the patients with HFS, for patients with trigeminal neuralgia, the ventrolateral medulla was not even explored at surgery because of the limited microsurgical exposure. In addition, a large number of studies were launched to evaluate the validity of MRI to identify NVC that might be causing hypertension. 1,10,12,21,24,28,29,35-37,39,45,50,55,57,58,61 Data from these publications has been reviewed in detail elsewhere. ${ }^{52}$ Briefly, most report a higher rate of images of vascular contact/compression at the ventrolateral medulla in patients with essential hypertension than in patients with normal BP. Of the publications with information on the side of the compression, a higher rate of left-sided over right-sided vascular contact/compression was found in patients with essential hypertension. ${ }^{1,37,39,45,50,57}$ However, according to a recent meta-analysis, significance was absent when analysis was confined to prospective studies $(\mathrm{p}=0.178$ for prospective vs $\mathrm{p}=0.001$ for retrospective studies), ${ }^{7}$ making the predictive value of MRI for selecting patients relatively uncertain.

Furthermore, a major limitation for MRI screening is the difficulty of discriminating whether a detected elongated arterial loop in relation with the ventrolateral medulla and adjacent CN IX-X REZ is the cause or the consequence of the raised BP. In the group of patients with secondary hypertension, the rate of NVC at the brainstem was less than the rate in the group of patients with primary-i.e., essential-hypertension $(p=0.01)$. However, when a megadolicho artery was present on imaging, this was not predominantly left sided. These studies do not allow definitive conclusions because their findings did not reach statistical significance due to the small number of patients enrolled. $1,21,35,36,39,45,57$

\section{Conclusions}

Arguments that vascular compression of the brainstem at the level of the CN IX-X REZ and adjacent ventrolateral medulla may be involved in some forms of hypertension seem convincing enough to incite the neurosurgical community to work further on vascular decompression as a possible treatment option for patients diagnosed with essential hypertension who may in fact have neurogenic hypertension due to vascular compression.

The main problem remains patient selection. MR images with high-resolution sequences allow identification of NVC with high sensitivity and specificity, but evidence of vascular contact/compression on MRI can well be the consequence of the elevated BP as well as the cause or a favoring factor of the hypertension disease. In spite of the large number of studies, the problem is still not solved.

Nevertheless, we think that in patients in whom medical treatment does not control BP, consideration of decompressive surgery might be justified, provided imaging shows a vascular conflict that is likely to be responsible.

The time has come for working groups, together with specialists in hypertension, to establish criteria for potential candidates for this treatment: patients whose hypertension has clinical peculiarities and/or pharmacological features in favor of a neurogenic origin and in whom imaging shows clear-cut evidence of vascular compression. Thus, studies could be launched with standardized protocols in patients with uncontrolled, unstable hypertension.

\section{Acknowledgment}

We thank Dr. Evelyne Decullier for her kind help with statistical analysis.

\section{References}

1. Akimura T, Furutani Y, Jimi Y, Saito K, Kashiwagi S, Kato $\mathrm{S}$, et al: Essential hypertension and neurovascular compression at the ventrolateral medulla oblongata: MR evaluation. AJNR Am J Neuroradiol 16:401-405, 1995

2. Alexander RS: Tonic and reflex functions of medullary sympathetic cardiovascular centers. J Neurophysiol 9:205-217, 1946

3. Amendt K, Czachurski J, Dembrowsky K, Seller H: Bulbospinal projections to the intermediolateral cell column: a neuroanatomical study. J Auton Nerv Syst 1:103-107, 1979

4. Armstrong DM, Ross CA, Pickel VM, Joh TH, Reis DJ: Distribution of dopamine-, noradrenaline-, and adrenalinecontaining cell bodies in the rat medulla oblongata: demonstrated by the immunocytochemical localization of catecholamine biosynthetic enzymes. J Comp Neurol 212:173-187, 1982

5. Barker FG II, Jannetta PJ, Bissonette DJ, Shields PT, Larkins MV, Jho HD: Microvascular decompression for hemifacial spasm. J Neurosurg 82:201-210, 1995

6. Blessing WW, Sved AF, Reis DJ: Arterial pressure and plasma vasopressin: regulation by neurons in the caudal ventrolateral medulla of the rabbit. Clin Exp Hypertens A 6:149-156, 1984

7. Boogaarts HD, Menovsky T, de Vries J, Verbeek ALM, Lenders JW, Grotenhuis JA: Primary hypertension and neurovascular compression: a meta-analysis of magnetic resonance imaging studies. J Neurosurg 116:147-156, 2012

8. Caverson MM, Ciriello J, Calaresu FR: Cardiovascular afferent inputs to neurons in the ventrolateral medulla projecting directly to the central autonomic area of the thoracic cord in the cat. Brain Res 274:354-358, 1983

9. Caverson MM, Ciriello J, Calaresu FR: Direct pathway from cardiovascular neurons in the ventrolateral medulla to the region of the intermediolateral nucleus of the upper thoracic cord: an anatomical and electrophysiological investigation in the cat. J Auton Nerv Syst 9:451-475, 1983

10. Ceral J, Zizka J, Eliás P, Solar M, Klzo L, Reissigová J: Neurovascular compression in essential hypertension: cause, consequence or unrelated finding? J Hum Hypertens 21:179-181, 2007

11. Ciriello J, Caverson MM: Bidirectional cardiovascular connections between ventrolateral medulla and nucleus of the solitary tract. Brain Res 367:273-281, 1986

12. Colón GP, Quint DJ, Dickinson LD, Brunberg JA, Jamerson KA, Hoff JT, et al: Magnetic resonance evaluation of ventrolateral medullary compression in essential hypertension. J Neurosurg 88:226-231, 1998

13. Colosimo C, Chianese M, Romano S, Della Chiara V, Vanacore N: Hemifacial spasm: a clinical and epidemiological study. Mov Disord 17:5235-5236, 2002

14. Colosimo C, Chianese M, Romano S, Vanacore N: Is hypertension associated with hemifacial spasm? Neurology 61:587, 2003 (Letter) 
15. Dahlström A, Fuxe K: Evidence for the existence of monoamine-containing neurons in the central nervous system. I. Demonstration of monoamines in the cell bodies of brainstem neurons. Acta Physiol Scand Suppl 232:1-55, 1964

16. Dampney RAL, Goodchild AK, Tan E: Vasopressor neurons in the rostral ventrolateral medulla of the rabbit. J Auton Nerv Syst 14:239-254, 1985

17. Defazio G, Berardelli A, Abbruzzese G, Coviello V, De Salvia R, Federico F, et al: Primary hemifacial spasm and arterial hypertension: a multicenter case-control study. Neurology 54:1198-1200, 2000

18. Dittmar C: Ueber die Lage des Sogenannten Gefässcentrums in der Medulla ablongata. Berichte ueber die Verhandlungen der saechsischen Gesellschaft der Wissenschaften zu Leipzig. Mathematisch Physikalische Klasse Leipzig 25:449-469, 1873

19. European Society of Hypertension/European Society of Cardiology Hypertension Guidelines Committee: Practice guidelines for primary care physician: $2003 \mathrm{ESH} / \mathrm{ESC}$ hypertension guidelines. J Hypertens 21:1179-1186, 2003

20. Geiger H, Naraghi R, Schobel HP, Frank H, Sterzel RB, Fahlbusch R: Decrease of blood pressure by ventrolateral medullary decompression in essential hypertension. Lancet 352:446-449, 1998

21. Giuffrida S, De Luca S, Lanza S, Papotto M, Restivo DA, Tomarchio L: Ipertensione arteriosa e compressione vascolare sul bulbo. Riv Neurobiol 44:295-300, 1998

22. Granata AR, Ruggiero DA, Park DH, Joh TH, Reis DJ: Lesions of epinephrine neurons in the rostral ventrolateral medulla abolish the vasodepressor components of baroreflex and cardiopulmonary reflex. Hypertension 5:V80-V84, 1983

23. Hökfelt T, Fuxe K, Goldstein M, Johansson O: Immunohistochemical evidence for the existence of adrenaline neurons in the rat brain. Brain Res 66:235-251, 1974

24. Hohenbleicher H, Schmitz SA, Koennecke HC, Offermann R, Offermann J, Zeytountchian H, et al: Neurovascular contact of cranial nerve IX and X root-entry zone in hypertensive patients. Hypertension 37:176-181, 2001

25. Howe PR: Blood pressure control by neurotransmitters in the medulla oblongata and spinal cord. J Auton Nerv Syst 12:95-115, 1985

26. Jannetta PJ, Gendell HM: Clinical observations on etiology of essential hypertension. Surg Forum 30:431-432, 1979

27. Jannetta PJ, Segal R, Wolfson SK Jr: Neurogenic hypertension: etiology and surgical treatment. I. Observations in 53 patients. Ann Surg 201:391-398, 1985

28. Johnson D, Coley SC, Brown J, Moseley IF: The role of MRI in screening for neurogenic hypertension. Neuroradiology 42:99-103, 2000

29. Kleineberg B, Becker H, Gaab MR, Naraghi R: Essential hypertension associated with neurovascular compression: angiographic findings. Neurosurgery 30:834-841, 1992

30. Leal PR, Hermier M, Froment JC, Souza MA, Cristino-Filho G, Sindou M: Preoperative demonstration of the neurovascular compression characteristics with special emphasis on the degree of compression, using high-resolution magnetic resonance imaging: a prospective study, with comparison to surgical findings, in 100 consecutive patients who underwent microvascular decompression for trigeminal neuralgia. Acta Neurochir (Wien) 152:817-825, 2010

31. Leal PR, Hermier M, Souza MA, Cristino-Filho G, Froment JC, Sindou M: Visualization of vascular compression of the trigeminal nerve with high-resolution 3T MRI: a prospective study comparing preoperative imaging analysis to surgical findings in 40 consecutive patients who underwent microvascular decompression for trigeminal neuralgia. Neurosurgery 69:15-26, 2011

32. Levy EI, Clyde B, McLaughlin MR, Jannetta PJ: Microvascular decompression of the left lateral medulla oblongata for severe refractory neurogenic hypertension. Neurosurgery 43:1-9, 1998

33. Levy EI, Scarrow AM, Jannetta PJ: Microvascular decompression in the treatment of hypertension: review and update. Surg Neurol 55:2-11, 2001

34. Møller AR, Møller MB: Does intraoperative monitoring of auditory evoked potentials reduce incidence of hearing loss as a complication of microvascular decompression of cranial nerves? Neurosurgery 24:257-263, 1989

35. Morimoto S, Sasaki S, Miki S, Kawa T, Itoh H, Nakata T, et al: Neurovascular compression of the rostral ventrolateral medulla related to essential hypertension. Hypertension 30:77-82, 1997

36. Morise T, Horita M, Kitagawa I, Shinzato R, Hoshiba Y, Masuya $\mathrm{H}$, et al: The potent role of increased sympathetic tone in pathogenesis of essential hypertension with neurovascular compression. J Hum Hypertens 14:807-811, 2000

37. Nakamura T, Osawa M, Uchiyama S, Iwata M: Arterial hypertension in patients with left primary hemifacial spasm is associated with neurovascular compression of the left rostral ventrolateral medulla. Eur Neurol 57:150-155, 2007

38. Naraghi R, Fahlbusch R: Microvascular decompression for the treatment of hypertension. Oper Tech Neurosurg 4:153161,2001

39. Naraghi R, Geiger H, Crnac J, Huk W, Fahlbusch R, Engels $\mathrm{G}$, et al: Posterior fossa neurovascular anomalies in essential hypertension. Lancet 344:1466-1470, 1994

40. Oliveira LD, Cardoso F, Vargas AP: Hemifacial spasm and arterial hypertension. Mov Disord 14:832-835, 1999

41. Polo G, Fischer C, Sindou MP, Marneffe V: Brainstem auditory evoked potential monitoring during microvascular decompression for hemifacial spasm: intraoperative brainstem auditory evoked potential changes and warning values to prevent hearing loss-prospective study in a consecutive series of 84 patients. Neurosurgery 54:97-106, 2004

42. Reis DJ, Ross CA, Ruggiero AR, Granata AR, Joh TH: Role of adrenaline neurons of the ventro-lateral medullai (the CI group) in the tonic and phasic control of arterial pressure. Clin Exper Hypertens A 6:221-241, 1984

43. Ross CA, Ruggiero DA, Joh TH, Park DH, Reis DJ: Adrenaline synthesizing neurons in the rostral ventrolateral medulla: a possible role in tonic vasomotor control. Brain Res 273:356-361, 1983

44. Ross CA, Ruggiero DA, Reis DJ: Projections from the nucleus tractus solitarii to the rostral ventrolateral medulla. J Comp Neurol 242:511-534, 1985

45. Säglitz SA, Gaab MR: Investigations using magnetic resonance imaging: is neurovascular compression present in patients with essential hypertension? J Neurosurg 96:10061012,2002

46. Sauvain MO, Magistris MR, de Tribolet N: Microvascular decompression of the facial nerve. Oper Tech Neurosurg 4:127-136, 2001

47. Segal R, Gendell HM, Canfield D, Dujovny M, Jannetta PJ: Cardiovascular response to pulsatile pressure applied to ventrolateral medulla. Surg Forum 30:433-435, 1979

48. Segal R, Gendell HM, Canfield D, Dujovny M, Jannetta PJ: Hemodynamic changes induced by pulsatile compression of the ventrolateral medulla. Angiology 33:161-172, 1982

49. Segal R, Jannetta PJ, Wolfson SK Jr, Dujovny M, Cook EE: Implanted pulsatile balloon device for simulation of neurovascular compression syndromes in animals. J Neurosurg 57:646-650, 1982

50. Sendeski MM, Consolim-Colombo FM, Krieger EM, da Costa Leite C: The spectrum of magnetic resonance imaging findings in hypertension-related neurovascular compression. Neuroradiology 48:21-25, 2006

51. Sindou M: Is there a place for microsurgical vascular decompression of the brainstem for apparent essential blood hyper- 
tension? a review. Adv Tech Stand Neurosurg 42:69-76, 2015

52. Sindou M, Leston J, Decullier E, Chapuis F: Microvascular decompression for primary trigeminal neuralgia: long-term effectiveness and prognostic factors in a series of 362 consecutive patients with clear-cut neurovascular conflicts who underwent pure decompression. J Neurosurg 107:1144-1153, 2007

53. Sindou M, Leston J, Howeidy T, Decullier E, Chapuis F: Micro-vascular decompression for primary trigeminal neuralgia (typical or atypical). Long-term effectiveness on pain; prospective study with survival analysis in a consecutive series of 362 patients. Acta Neurochir (Wien) 148:1235-1245, 2006

54. Sindou MP: Microvascular decompression for primary hemifacial spasm. Importance of intraoperative neurophysiological monitoring. Acta Neurochir (Wien) 147:1019-1026, 2005

55. Smith PA, Meaney JF, Graham LN, Stoker JB, Mackintosh AF, Mary DA, et al: Relationship of neurovascular compression to central sympathetic discharge and essential hypertension. J Am Coll Cardiol 43:1453-1458, 2004

56. Tan EK, Chan LL, Lum SY, Koh P, Han SY, Fook-Chong SM, et al: Is hypertension associated with hemifacial spasm? Neurology 60:343-344, 2003

57. Thuerl C, Rump LC, Otto M, Winterer JT, Schneider B, Funk $\mathrm{L}$, et al: Neurovascular contact of the brain stem in hypertensive and normotensive subjects: MR findings and clinical significance. AJNR Am J Neuroradiol 22:476-480, 2001

58. Watters MR, Burton BS, Turner GE, Cannard KR: MR screening for brain stem compression in hypertension. AJNR Am J Neuroradiol 17:217-221, 1996

59. Whithworth JA, World Health Organization, International Society of Hypertension Writing Group: World Health Organization (WHO)/International Society of Hypertension (ISH) statement on management of hypertension. J Hypertens 21:1983-1992, 2003

60. Zanchetti A: Guidelines for the management of hypertension: the World Health Organization/International Society of Hypertension. J Hypertens (Suppl 13):S119-S122, 1995

61. Zizka J, Ceral J, Elias P, Tintera J, Klzo L, Solar M, et al: Vascular compression of rostral medulla oblongata: prospective MR imaging study in hypertensive and normotensive subjects. Radiology 230:65-69, 2004

\section{Author Contributions}

Conception and design: Sindou. Acquisition of data: Sindou, Mahmoudi. Analysis and interpretation of data: all authors. Drafting the article: Sindou, Mahmoudi. Critically revising the article: Sindou. Reviewed submitted version of manuscript: Sindou, Brînzeu. Approved the final version of the manuscript on behalf of all authors: Sindou. Statistical analysis: Brînzeu. Administrative/technical/material support: all authors. Study supervision: Sindou.

\section{Supplementary Information}

Previous Presentation

Portions of this work have been presented in the form of oral presentations to the annual reunion of the French Speaking Society of Neurosurgery: "Reunion annuelle d'hiver de la SNCLF. Reunion annuelle de Paris." Carrousel du Louvres, Paris, France, November 26-28, 2012.

\section{Correspondence}

Marc Sindou, Department of Neurosurgery, University of Lyon 1, Hôpital Neurologique "Pierre Wertheimer," Groupement Hospitallier EST, 59 Blvd. Pinel, Lyon 69003, France. email: marc. sindou@chu-lyon.fr. 